\title{
Development of the RFID Based Library Management and Anti-Theft System: A Case of East African Community (EAC) Region
}

\author{
Deo Irankunda ${ }^{1}$, Ramadhani Sinde $^{2}$, Neema Mduma ${ }^{3}$, Mussa Ally. Dida ${ }^{4}$ \\ Scholar $^{1}$, Lecturer $^{2,3}$ Senior Lecturer ${ }^{4}$ \\ School of Computational and Communication Sciences and Engineering \\ Nelson Mandela African Institution of Science and technology
}

Arusha-Tanzania

\begin{abstract}
Radio Frequency Identification (RFID) Systems are becoming very useful in our daily life due to its advantages such as reduction of human error, theft prevention, time consuming reduction, the auto identification of targeted objects, business processes automation etc. RFID systems has been applied in library to manage items and library operations. Different approaches have been adopted in library management system in the East African region unfortunately some challenges including theft, pages removal, non-customer satisfaction, high cost of used system etc. are still persisting. To address these challenges, an RFID based library management and anti-theft system has been developed to East African Community (EAC) library. It focused on the use of Ultra High Frequency (UHF) band which enable readers and tags to transmit and receive data at long range. The developed system facilitates users to borrow and return library items using RFID modules and enable librarians to monitor, record library activities and prevent no issued item to cross the library entrance or exit.
\end{abstract}

Keywords: RFID, Library Management System, Anti-Theft, Ultra High Frequency.

\section{INTRODUCTION}

A library is a curated collection of sources of information and similar resources, selected by experts and made accessible to a defined community for borrowing, reading, often a quiet environment for conductive study [1]. It is a place where people can get information in a different format found in various materials such as books, newspapers, manuscripts, films, maps, documents, CDs, cassettes, prints, e-books, audiobooks etc. A library is an important part of the academic sector as well as professional sectors [2]. It can appear in different types such as academic, private, public etc. and its size depend on the number of items it contains [3]. Having a big number of items in the library may bring a lot of challenges when comes to the purpose of management and achievement of fixed goals and objectives of library. According to Padmaj 2019, a library to accomplish its objectives and goals needs efficiency in its operations, which lies on how the books are arranged and how easily users can get books of their choice, issuing and return borrowed items[4]. Koneru, 2004 defined library management as the action of keeping an eyes on library department functions and maintain all records of the library in such a way the library stays in an operative manner and keeps the constant track of all library items in store. According to Smith et al., 2007, library management is the system developed for handling basis functions of a library, providing a complete administration solution of a library's technical function and services to the defined community[6]. It includes areas such as books circulation or reviewing, classification of materials, catalogue management, patron management, online access, search facility etc. [7]. Furthermore, the presence of Information and Communication Technology (ICT) has become a concern of libraries and institutions around the world and changed their working way. According to M. Singh, 2014, a library assistant at Guru Nanak Dev Engineering College, Ludhiana (GNDEC), ICT has brought a remarked change in different prospectus of human endeavor. As libraries remain the primary source of information for thousands of people, their managements have been taken as a key features of many organizations including EAC which need to be improved and reinforced. On handling library management, several technologies such as barcoding, RFID, software based, can be used in the prospectus to automate activities in general. Despite works which have been done, libraries around the world are still experiencing several challenges including theft, pages removal, high cost etc. followed by addition of improvised budget for item replacement and maintenance. Therefore, this study aimed to develop RFID based library management and anti-theft system to 
provide features of maximization of time, preventing theft and keeping track of library items using the radio waves. The system automates the book handling process including checkout, check-in, shelf management, item borrowing and returning without requiring more of human interaction and generate alerts in case of non-issued items across the exit doors of library.

\subsection{RFID in the Library}

A radio frequency identification is a computing technique based on the use of radio waves for transmitting and receiving data between a reader and movable item to identify, categorize and track wirelessly [10]. It facilitates the library transactions with the help of RFID modules without human (manual) typing, provides a monitoring module and increase security. Through this technology, books or others items are easily located in case of misplacement. The method is fast, secure and provides a unique identification and backend integration. RFID system comprises of three main components which interact with computer system:

- RFID readers

- RFID tags/labels

- Antenna

An RFID reader and transponders are designed with a microchip inside to deals with signal processing and antenna for sending and receiving data via radio waves. Transponders exists in two types which can either be actives or passives with non-battery inside and powered by the radios waves from the RIFD reader [11] [12].

\section{RELATED WORKS}

Several researches have been done and come up with different computerized methods to be used for overcoming limitations caused by Manual Library Management System (MLMS). The barcode technology is one of computerized system adopted in many libraries which involves the use of software and hardware. In 2005, Singh \& Sharma designed a system-based barcode identification with the aim of reducing time consuming and overcoming others challenges found in manual system[14]. However, the system exposed to a lot of limitations: requires a physical sight to scan a barcode which involve the human intervention unable to read more than one barcode at once and its readability can be affected by moisture, dirty, absorption, packaging etc. Furthermore, Hamid,2012 described that there are no perfect system for actual tracking of books in the library and display their location [15]. For that reason, the system was developed based on UHF readers to read tag at high distance compare to other frequencies. UHF RFID tag was placed at the shelves and big number of RFID reader was used. Similar system has been developed to pilot a university library[16]. The study used Graphical User Interface (GUI) to support all necessary library functionalities and user needs. Shelf antennas that were optimized with a target of maximize tag readability as well as minimizing the pollution of electromagnetic in the vicinity cabinet were used [17]. However, the systems were very cost effective due to requirements such as confined reading area and positioning ability to know where the label is along to the shelf. [18] observed that books and pages are disappearing at University of Lincoln due to bad behavior of employees and students. Regular library checks in, security gates and maintenance to avoid failures was recommended. According to Alexander, bag searching acts was a deterrent and heightens security awareness[19]. However, this approach didn't succeed to stop the theft. Therefore, solutions that incorporate technologies such as CCTV camera were integrated and brought more advantages.

\section{MATERIALS AND METHODS}

\subsection{Case study}

The study was carried out in East African region, particularly at East Africa Community secretariat, in the Information Resource Centre (IRC) department located in Arusha-Tanzania and in the Vivian A. DAKE Memorial library of Hope Africa University located in Bujumbura-Burundi.

\subsection{Data Collection Methods}

On carrying this study, data was gathered from library staff and other users to determine challenges and needs for library management. The collected data were classified into two categories such as primary and secondary data. Primary data are those which were collected afresh and for the first time and thus happen in the original form, not published yet and more reliable while secondary data were collected from the published materials.

\subsubsection{Primary Data}

The primary data were obtained from librarians of Information Resource Centre of EAC and from library admin and students from Hope Africa University (HAU). Discussion, observation, interviews, questionnaire and face to face conversation were methods used to obtain all needed information. Discussion was conducted to assess the existing system and determine their weakness and 
strength. Observation was conducted to both libraries to observe how services were delivered to library's patrons while interview was conducted to librarians to investigate scenario which libraries were going through in embarking an automation library. Furthermore, questionnaire was conducted to librarians and users to identify the level of users' satisfaction and challenges met when they visited library. Also, face to face conversation method was used when conducting interview with library admin to identity and agree on requirements of the developed system. Google form was used as the technical tool to capture data from respondents.

\subsubsection{Secondary Data}

In order to grasp relevant information of the developed system documentation method was used. Books, reports, various publications, internet articles etc. were analyzed to identity what has been done by other researchers together with observations, recommendations and solutions proposed.

\subsubsection{Data analysis}

Data processing was conducted in prior of analysis in order to make it consistent. Open refine and google sheets are the tools used to process data, reshapes and intelligently batch edit. Tables were used for quantitative data analysis due to the influence of interactive features and ability of proving efficient results.

\subsection{Description of the developed system}

The developed system based on UHF RFID where the RFID labels was embedded on library items and user was assigned a smart card. It comprises two main parts: development of software and hardware integrations. The first part provides diverse features via interfaces: user, admins(librarians) and super-admin to help users to interact with the system and the second focuses on hardware integration. In addition of RFID devices, the CCTV devices were used to enable to all activities within library to be recorded. In engineering, data flow diagram is tools that illustrates the flow of data through the interaction of different entities of the system. It is a graphical depiction of the flow of information that are applied to data movement from the input to output. Figure 1 show how used devices are interconnected and figure 2 depicts the interactions between LMS and external entities.

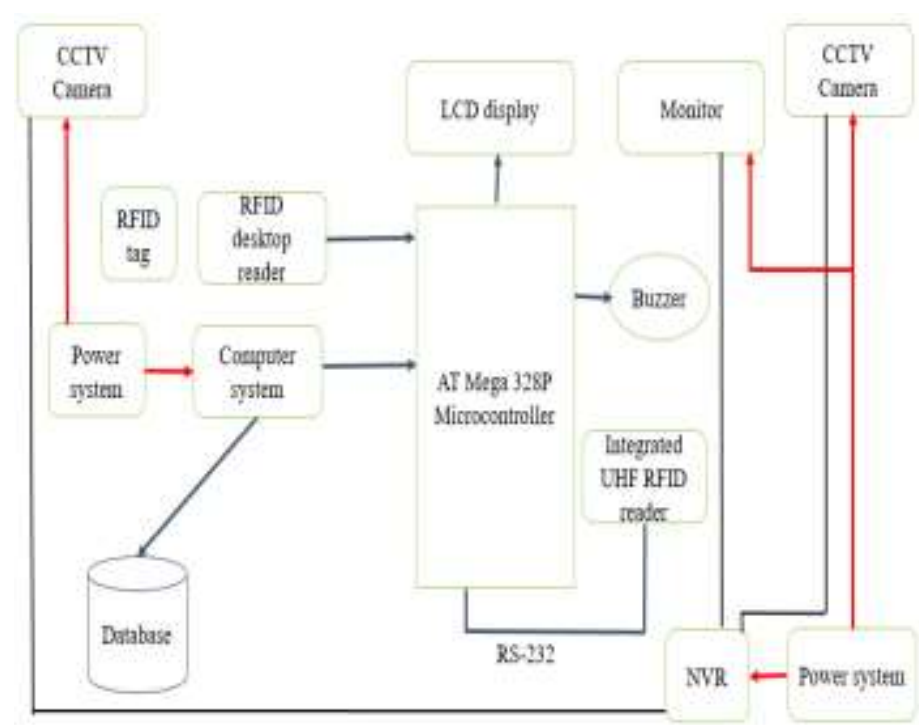

Figure 1: System block diagram 


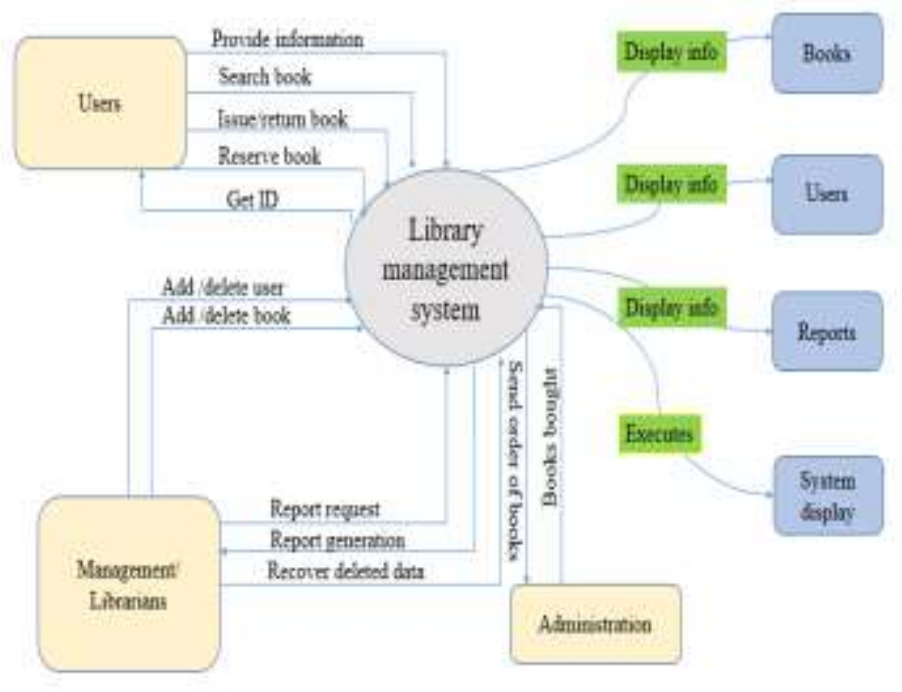

Figure 2: Context diagram

\subsection{System Requirements}

\subsubsection{Software Requirements and Tools Used}

During development of this system, windows operating system version 10 was used. The selection was based due to the fact that it is stable, supports more features and user friendless. Others tools used to develop the library web based focused on front end such Cascading Style Sheets (CSS), Hyper Text Markup Language (HTML) and Java script, back end: Code Igniter, MySQL, XAMPP server and sublime programming editor.

\subsubsection{Hardware tools used and their specifications}

ATMEGA328P Microcontroller is high performance, low power controller from Microchip, designed with 8bit microcontroller based on AVR RISC architecture. It is mostly used in low powered and low cost projects and autonomous where microcontroller is required. ATMEGA 382P has 28 pins chip in total, analog, digitals, power and ground pins as shown in the figure 7 below and operate at $0 \mathrm{~V}$ to $5 \mathrm{~V}$ (figure 3 ).

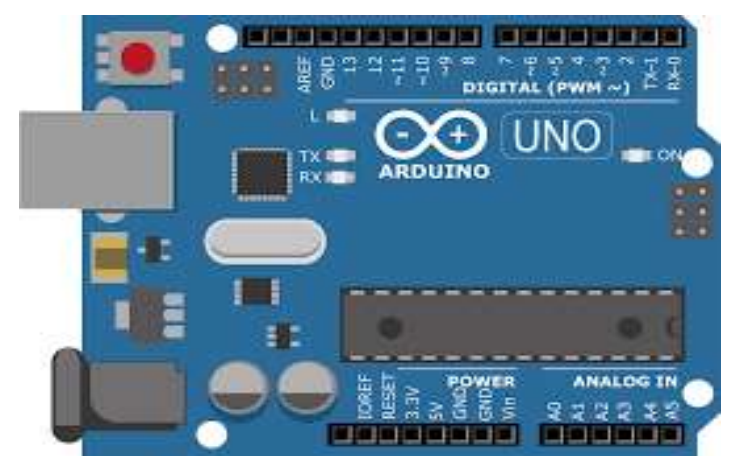

Figure 3: AT Mega 328P Microcontroller

RFID tag for users: RFID Tag is a kind of transceiver device used to exchange data with radio frequency identification reader through radio frequency waves. It has two main parts whose Integrated Circuit (IC) used for data processing and storing as well as modulating and demodulating radio waves received/sent and antenna as second part. 


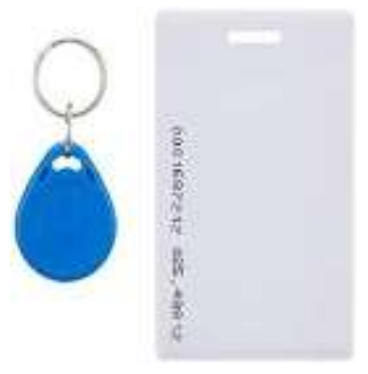

Figure 4: RFID Tag for users

Buzzer: Buzzer is a kind of voice device that converts audio model into sound signal. According to different design and application, it can produce music sound, flute sound, alarm sound, electric bell and other different sounds. A buzzer has 2 pins and a DC operating voltage of $5 \mathrm{v}$.

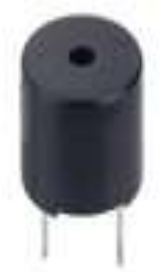

Figure 6: Buzzer

LCD display: A liquid-crystal display is an electronic device that use liquid crystal to display data from inputs devices electronically optical modulated and used in most cases, as user interfaces of the system. LCD disposes 16 pins, operates at $5 \mathrm{v}$ DC voltage. A RC2004A is monochromatic 20x4 alphanumeric LCD able to display 20characters at each 4rows adopted to be used in this system.

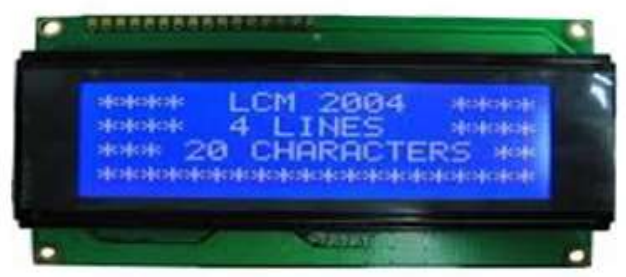

Figure 7: LCD display

UHF RFID Integrated reader VI-83TF: A UHF RFID reader is a device using an Ultra-High Frequency band whose range is between $84 \mathrm{OMHz}$ and $960 \mathrm{MHz}$. It has an extended read range compared to other LF, HF readers. It has features of STMicroelectronics STM Cortex-M3 core CPU processor with ultra-low power consumption and ultra-high performance which makes the reader program and interface run more stable and faster. It can use standard interfaces (TCP/IP, RS485, RS232, Wiegand interface) and optional (wireless WIFI, Bluetooth) with an operating DC voltage of 9-24V and temperature of $-20^{\circ} \mathrm{C} \sim$ $+60^{\circ} \mathrm{C}$.

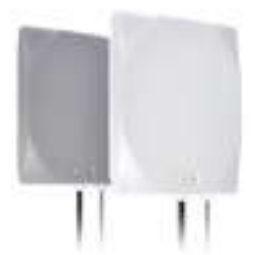

\section{Figure 8: UHF RFID Integrated reader}

UHF RFID Book archive tag LA-86C: RFID labels have a high security performance, a global unique code identification and widely used in libraries, database rooms and secrets archives [20]. UHF RFID book labels are compatible with EPC CLASS1 Gen 2 / ISO 18000-6C protocol, able to read and transmit data within a reading range of 0-5 meters depending on reader's performance and work with a temperature of $-20^{\circ} \mathrm{C}+50^{\circ} \mathrm{C}$. 


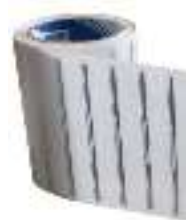

Figure 9: UHF RFID Book label

\section{RESULTS}

\subsection{Demographics characteristics}

Assessment demographic of respondents in this study was very inevitable to assess attitude and prospective of library stakeholders through the use of Information and Communication Technology (ICT). This study examined gender, age, education level and experience of using internet and library. Table 3 below demonstrates the socio-demographic details of each category of respondents. The total number of 105 respondents were examined with number of male greater than number of female respondents. For the case of education level and age, the majority of respondents acquired bachelor degree with ages ranged from 18 to 40 .

Table 2: Demographic characteristics of respondents

\begin{tabular}{llcc}
\hline \multicolumn{2}{l}{ Demographic features } & Respondents & Percentage \% \\
\hline Gender & male & 62 & 59 \\
& Female & 43 & 41 \\
& under 18 & 1 & 1 \\
Ages & $18-30$ & 57 & 54.3 \\
& $31-40$ & 41 & 39 \\
& $41-60$ & 6 & 5.7 \\
\multirow{5}{*}{ Education } & Above 60 & 0 & 0 \\
& Secondary & 6 & 5.7 \\
& Bachelor & 46 & 43.8 \\
& Masters & 36 & 34.3 \\
& PhD & 17 & 16.2 \\
\hline
\end{tabular}

\subsection{Existence of libraries and its use in EAC region}

Figure 10 shows that $95.2 \%$ of academic's institution in the EAC region have libraries where students, lecturers and researches use to search information related to works. Figure 11 illustrated that $27.8 \%$ of respondents visited library several times a week while $2.6 \%$ of respondents visited library rarely. Users visit library for different purposes such find book, articles, magazines, doing a self-study etc.

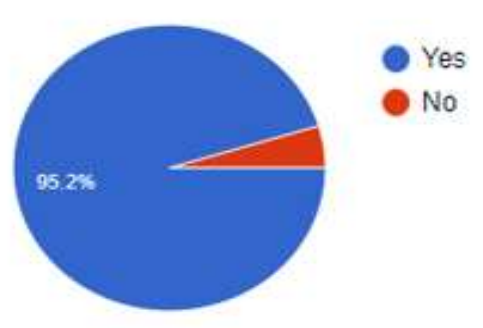

Figure 10: Existence of library in academic's institutions

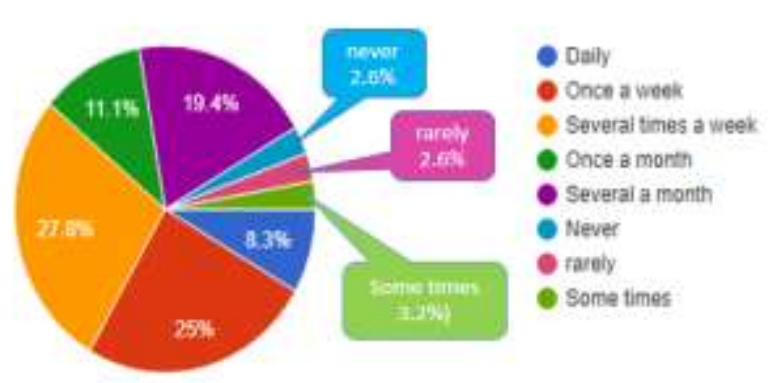

Figure 11: Number of times of visiting library

\subsection{Library management system used}

A survey was also conducted to identify which libraries management system were mostly used in the region. The results showed that $61 \%$ of library were computerized which means the use of ICT technology has been integrated in library management and $39 \%$ were using manual methods. However, the data collected from respondents illustrates that libraries are using different computerized methods such as software $(51.9 \%)$ while Q-R technology is not mostly used (0\%) (Table 3). 
International Journal of Advances in Scientific Research and Engineering (ijasre), Vol 7 (5), May-2021

Table 3: Library management system used in EAC region

\begin{tabular}{lccc}
\hline LMS & \multicolumn{2}{c}{ Respondents } & Percentage \% \\
\hline Types & Computerized & 64 & 61 \\
& Manual & 41 & 39 \\
Technology used & in computerized & \\
RFID & 11 & 13.9 \\
Barcode & 21 & 26.6 \\
Software & 41 & 51.9 \\
Q-R & 0 & 0 \\
\hline
\end{tabular}

\subsection{Internet usage and technological devices}

A survey was also conducted to identify how internet were used in academic sector and which devices were mostly used. Results from the respondents showed that $99 \%$ of educated people accessed internet with different proportions of times. As shown in the figure 13, 43.8\% accessed internet daily, $44.8 \%$ several times a week while $1 \%$ never accessed it. Figure 14 shows devices which were used to access internet, $81.9 \%$ access internet using laptop while $19 \%$ accessed using tablet.

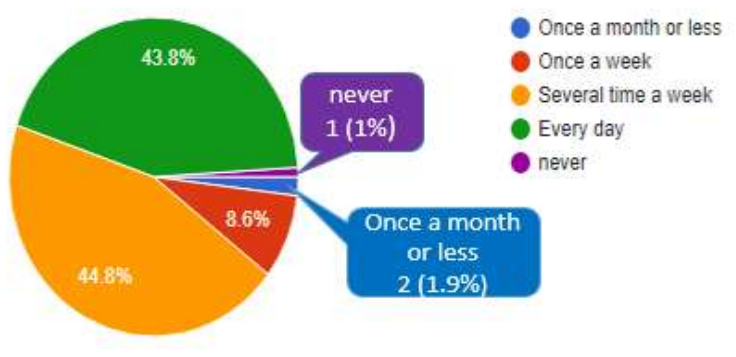

Figure 13: Number of times that internet is accessed

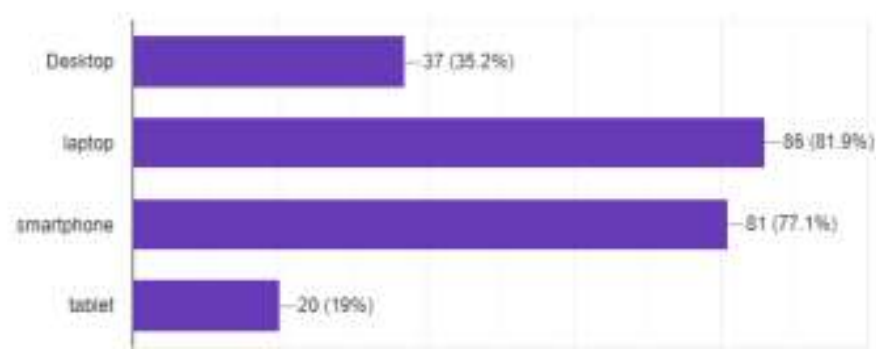

Figure 14: Devices used to access internet

\subsection{Types of security used in existing system}

To identify the level of library security, a survey was conducted and results showed that libraries used different security measures. $80.9 \%$ of libraries strictly forbid to enter in the library with a handbag while $0.9 \%$ revealed used alarming systems at the library exit (Table 4).

Table 4: Methods used to prevent loss of library items

\begin{tabular}{lcc}
\hline Methods used & Respondents & $\%$ \\
& & 65 \\
\hline User's bags checking at the exit of library & 65 & 80.9 \\
It is strictly forbidden to enter with a handbag & 85 & 39.04 \\
Each user is required to sign in the library book & 41 & 20.9 \\
Surveillance camera & 22 & 18.09 \\
Guards are standing at the entrance and exit & 19 & 0.9 \\
Using an alarming system at the library exit & 1 & 0.9 \\
Librarians and guards make circulations in & 1 & \\
the library when users are inside & & 11.4 \\
Using biometric technology to enter & 12 & \\
\hline
\end{tabular}

\subsection{Challenges in library}

In order to understand challenges that facing libraries, the survey was conducted and results showed that pages removal and theft exist. $42.85 \%$ of respondents confirmed theft occurred several times a year while $15.23 \%$ denied. The results continued to show that $68.57 \%$ of respondents responded positively that books missed pages while $31.42 \%$ responded negatively pages (Table 5).

Table 5: Challenges founds in existing systems

\begin{tabular}{ccccc}
\hline Subject & Number of times & respondents & Percentage & $\%$ \\
& Once a day & 0 & 0 & \\
Once a week & 2 & 0.019 & \\
\hline
\end{tabular}


International Journal of Advances in Scientific Research and Engineering (ijasre), Vol 7 (5), May-2021

\begin{tabular}{lll}
\hline Several times a week & 4 & 0.38 \\
Theft in library & 6 & 0.57 \\
Once a month & 7 & 0.66 \\
Several times a month & 25 & 23.80 \\
Once a year & 45 & 42.85 \\
Several times a year & 16 & 15.23 \\
Never & 72 & 68.57 \\
Book pages removed Yes & 33 & 31.42 \\
No & & \\
Times used in borrowing process & 11 & 10.6 \\
Equal or less than 5 min & 42 & 40.4 \\
10 min & 38 & 36.5 \\
15 min & 13 & 12.5 \\
More than 15 min & &
\end{tabular}

\subsubsection{Problem of existing system}

After observing existing library management systems both manual and computerized, the following problems were highlighted:

(i) Loss of data: In some of the systems, data are not centralized and they are kept in a book or peace of papers.

(ii) Time consuming: Time consuming tends to differ from manual to barcoding system. Manual system takes a lot of time in report generation and users cannot be tracked easily.

(iii) Error: Manual and barcoding system are exposed to human error.

(iv) Theft: Each year in many libraries around the world including libraries of East African region loss items.

(v) Page removing: The act of losing pages which contains important information.

\subsection{RLMAS database implementation}

The database of this system was developed and supported by MySQL database management and PHP scripts for user's web connectivity. Figure15 illustrates number of tables used to develop the web based of this system and associations in the application.

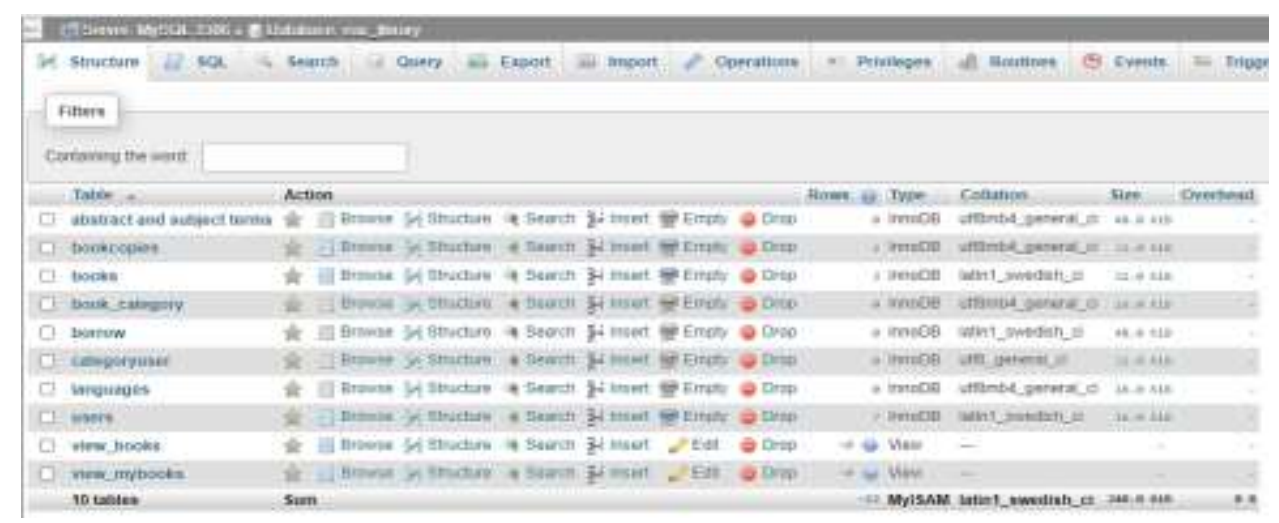

Figure 15: Database implementation

\subsection{Input and Output design}

The developed application is responsive for different ICT devices such as laptop, desktop, smartphone etc. The figures $16,17,18,19$ and 20 show modules used to enable users and librarians to perform the desired tasks. The home page gave an overview of the system and presented a login panel where each category of users is required to enter credentials. Once login, users were directed to pages containing information depending to their categories.

\section{Book borrow module}

All registered users have rights to borrow book copies while original books are restricted. By clicking the borrow button, users are required to enter details by swapping tag on desktop reader then personal information such name, user ID and emails will be appeared in the form. Then, user continues with scanning the preferred book as shown in figure 20. However, the process of borrowing can be denied due to the following case: 
(i) The allowed number of item to be borrowed has been exceeded ( 2 or 3 items are allowed but depending on library regulations).

(ii) Users didn't return the previous borrowed items.

To return borrowed item, borrowers is also required to use their tag ID then scan borrowed item. When users are not around library, the system gives ability to reserve a book in the interval of 48 hours.

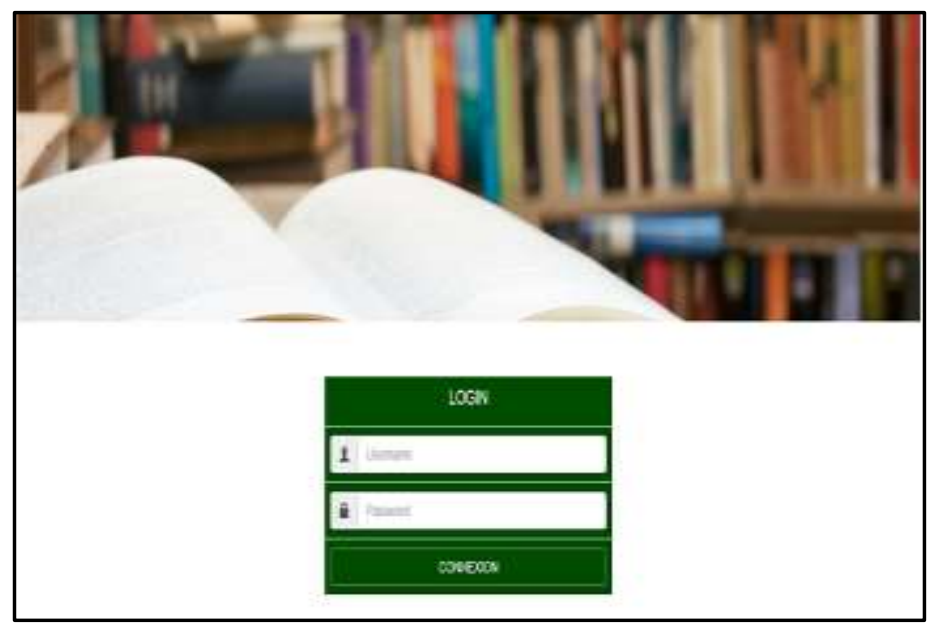

Figure 16: Home and login page

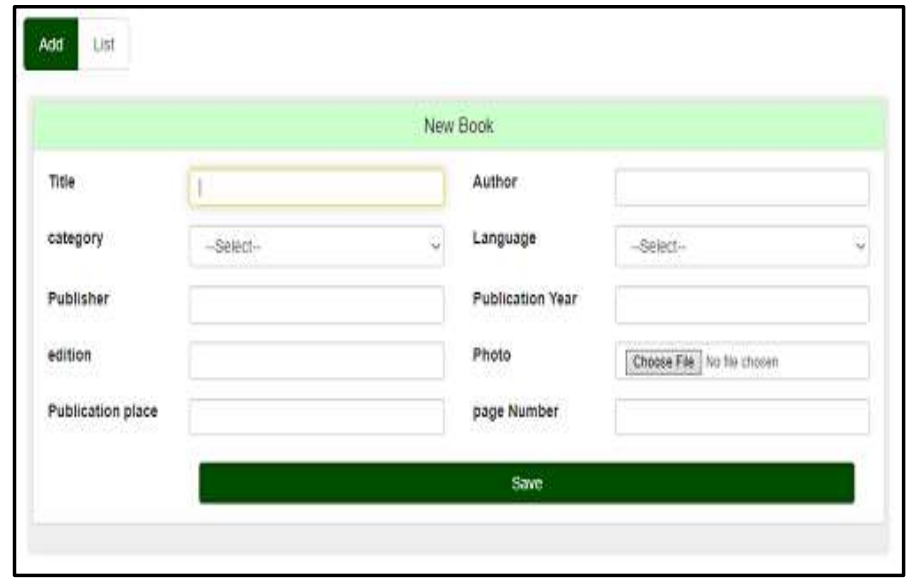

Figure 18: Book registration

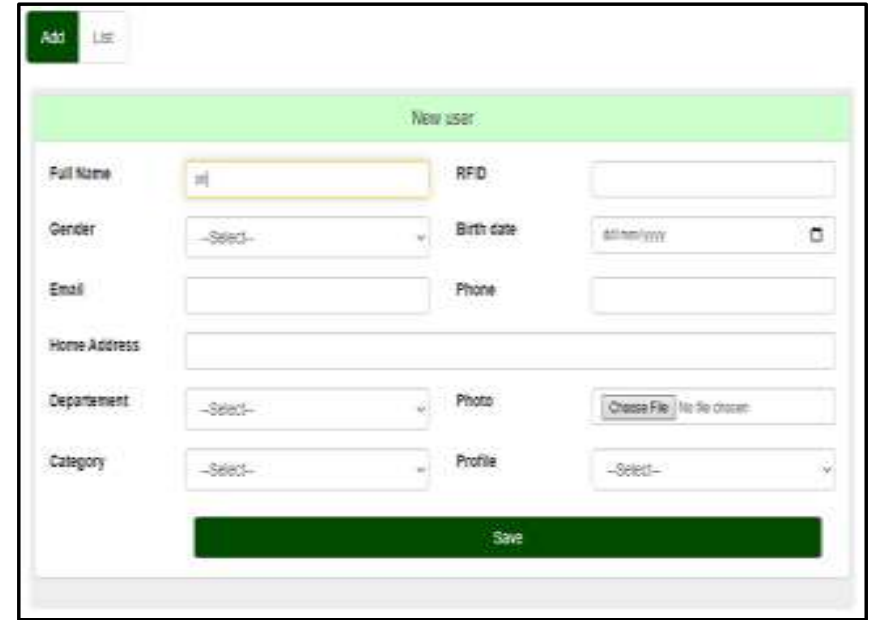

Figure 17: User registration

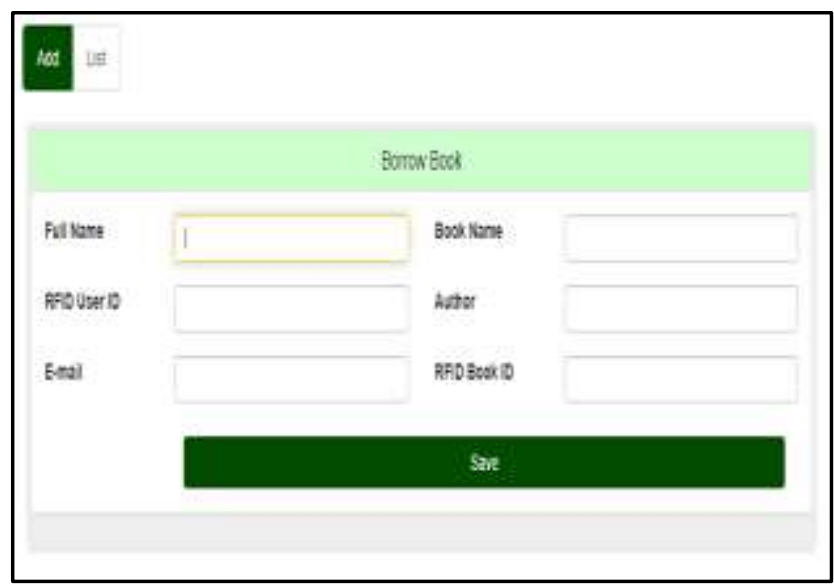

Figure 19: Book borrow

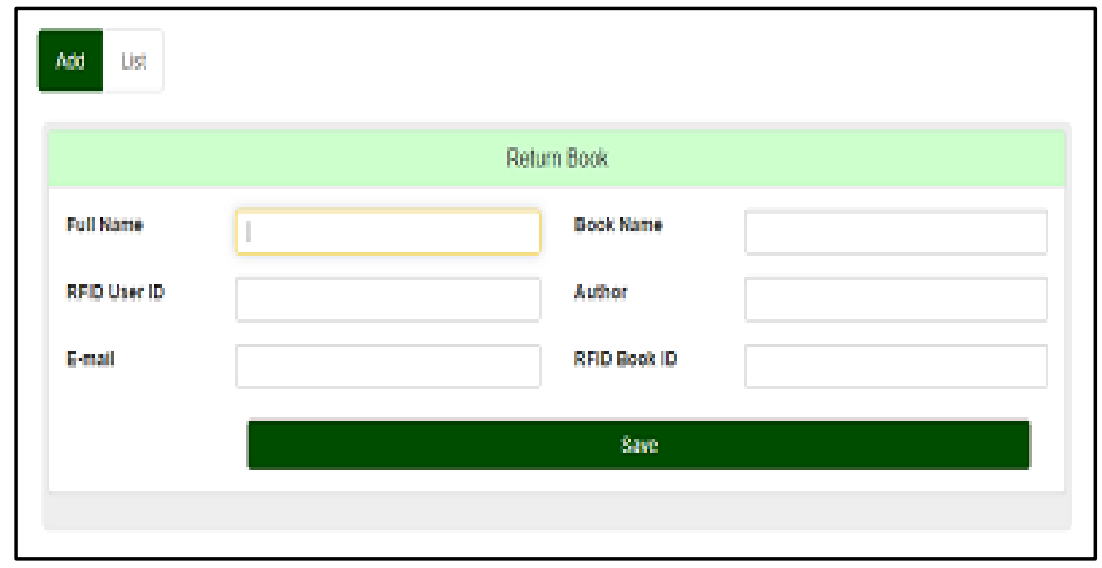

Figure 20: Book return

\section{DISCUSSION}

Many educational institutions in the EAC region dispose libraries which are highly visited by people of different range of studies with various purpose. They play significant role of supporting students, researchers and lecturers to find needed information. Many library management systems were implemented to solve problem and vulnerabilities of traditional and barcode system in 
library unfortunately problems still appearing and affect libraries in different points [13]. To address this issue, a compatible system able to read hidden items even at big distance and generate alarm has to be developed and implemented. The measurement and identification of vulnerabilities in existing systems has been done first then collection of requirements of the new system. A radio frequency identification is a computing advanced technique able to transmit and receive data between a reader and movable item to identify, categorize and track wirelessly [10]. The previous study demonstrated that RFID even brought remarkable advantage, cannot be used for record and become incompatible when tags or labels have been removed on targeted objects reason why CCTV become more advantage. It could be a good pleasure for future work to find a system able to fight against this page removal.

\section{CONCLUSION}

Library provides ability for researchers to easily get resources and information needed and facilitate them to have an opened mind. This study aimed to develop a system for solving existing challenges by keeping all library resources well managed, secured as well as granting a high level of accessibility. The developed system 'RFID based Library Management and anti-Theft system" (RLMATS) focused on the use of Ultra High Frequency (UHF). It facilitated users to borrow and return library items with the help of RFID enabled modules without more human intervention. This system leads a significant time management in operation, enhances customer service and provides security of the library items by issuing an alert if non-issued item detected when user cross library entrance or exit. Furthermore, the system was not developed to meet needs of only institutions of East African region rather than outside the region.

\section{REFERENCE}

[1] M. Dhanalakshmi and U. Mamatha, "RFID Based Library Management System,” Proc. ASCNT 2009, CDAC, Noida, India, vol. 2, no. 1, pp. 227-234, 2009.

[2] I. E. . Isebe, "Cause and effects of theft and mutilation of information materials in academic library services in delta state,” Cause Eff. Th. mutilation Inf. Mater. Acad. Libr. Serv. delta state, vol. 4(10), pp. 76-82., 2014.

[3] A. T. Tosin, "Library Management System By Being a Project Report Submitted To the Department of Computer Science , Faculty of Science, Federal University Oye Ekiti, Ekiti State, Nigeria in Partial Fulfilment of the Requirement for the Award of Bachelor of Science (," p. 70, 2015, [Online]. Available: https://www.academia.edu/33632232/LIBRARY_MANAGEMENT_SYSTEM.

[4] L. L. Padmaj P kumar*1, Najiya Masood*2, Sooraj Kumar S*3, Jismi Rajan*4, "Library Management Using RFID," Int. Res. J. Eng. Technol., vol. Volume: 06, no. Issue: 05, pp. 1586-1592.

[5] I. Koneru, "RFID Technology : A Revolution in Library Management," Library (Lond)., pp. 11-13, 2004.

[6] R. G. Smith, F. D. Menalled, and G. P. Robertson, "Temporal yield variability under conventional and alternative management systems," Agron. J., vol. 99, no. 6, pp. 1629-1634, 2007, doi: 10.2134/agronj2007.0096.

[7] S. Satrusallya and A. Wunnava, "RFID technology based library management system," Int. J. Innov. Technol. Explor. Eng., vol. 8, no. 11 Special Issue, pp. 937-941, 2019, doi: 10.35940/ijitee.K1171.09811S19.

[8] M. Singh, "A snapshot of traditional library to modern library using bar code technology: an experience of central library GNDEC, Ludhiana,” J. Adv. Libr. Inf. Sci., vol. 3, no. 2, pp. 146-149, 2014.

[9] M. E. Bitter-Rijpkema, S. Verjans, and R. Bruijnzeels, "The Library School: Empowering the sustainable innovation capacity of new librarians," Libr. Manag., vol. 33, no. 1-2, pp. 36-49, 2011, doi: 10.1108/01435121211203301.

[10] P. Grover and A. Ahuja, "Radio Frequency Identification Based Library Management System," Int. J. Adv. Comput. Sci. Appl., vol. 1, no. 1, 2010, doi: 10.14569/ijacsa.2010.010107.

[11] F. Nisha, "Implementation of RFID technology at defence science library, DESIDOC: A case study," DESIDOC J. Libr. Inf. Technol., vol. 38, no. 1, pp. 27-33, 2018, doi: 10.14429/djlit.38.1.12351.

[12] S. Vijayagowri and M. E. Mrs. B. Kousalya., "INTELLIGENT LIBRARY MANAGEMENT SYSTEM USING GSM AND RFID,” Int. J. Res. Comput. Appl. Robot., vol. Vol.4, no. 6, p. 33, 2016.

[13] G. Singh and M. Sharma, "Barcode technology and its application in libraries and Information centers," Int. J. Next Gener. Libr. Technol., vol. 1, no. 1, pp. 1-8, 2015.

[14] E. Edwards and P. Orukpe, "Development of a RFID Based Library Management System and User Access Control," Niger. J. Technol., vol. 33, no. 4, p. 574, 2014, doi: 10.4314/njt.v33i4.19.

[15] S. B. A. Hamid, A. Diyana Rosli, W. Ismail, and A. Z. Rosli, "Design and implementation of RFID-based anti-theft system," Proc. - 2012 IEEE Int. Conf. Control Syst. Comput. Eng. ICCSCE 2012, no. November, pp. 452-457, 2012, doi: 
International Journal of Advances in Scientific Research and Engineering (ijasre), Vol 7 (5), May-2021

10.1109/ICCSCE.2012.6487188.

[16] D. Makhija and P. K. Chugan, "RFID Based Library Management System: The Benefits and Challenges,” 19th Int. Conf. Manag. NICOM, pp. 219-231, 2016.

[17] Y. Yuan and D. Yu, "UHF RFID shelf solution with cascaded reader antenna and positioning capability," 2012 IEEE Int. Conf. RFID, RFID 2012, no. April 2012, pp. 149-156, 2012, doi: 10.1109/RFID.2012.6193043.

[18] D. L. A. Mansfield, "Reducing Book Theft at University Libraries," Libr. Inf. Res., vol. 33, no. 103, pp. 10-15, 2009, doi: 10.29173/lirg98.

[19] A. Alexander, Review of Public Libraries, Archives and Museums: Trends in Collaboration and Cooperation, vol. 2, no. 2. 2010.

\section{Author's profile}
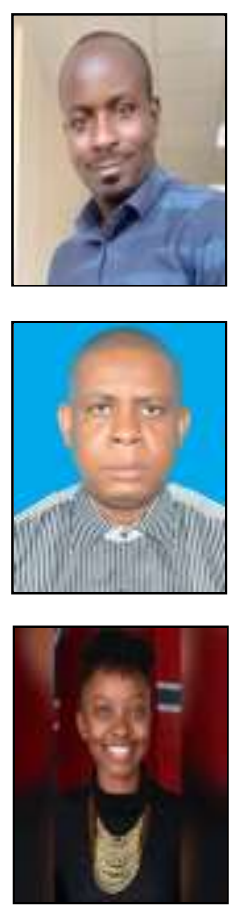

Deo Irankunda born at Mubanga-Muhuta commune, Rumonge province of Burundi. He is a Msc candidate in Embedded and Mobile System, specializing in Embedded System at Nelson Mandela African Institution of Sciences and Technology. He has a background in telecommunications engineering and management in the specialty of Network and System securitiy obtained at Hope Africa University in Bujumbura Burundi. His interst lie in Information Communication and Technololy of development in educational sector, Health and internet gouvernance. Email: irankundad@ nm-aist.ac.tz

Ramadhani Sinde works as lecturer in the School of Computational and Communication Sciences and Engineering (CoCSE) at Nelson Mandela African Institution of Science and Technology (NM-AIST). His research interests include Internet of Things and Embedded Systems, mobile computing, modelling and performance evaluation of wireless sensor networks, wireless and mobile communication. Sinde has authored and co-authored more than 10 papers in internationally refereed journals and conferences. He is a Queen Elizabeth Scholarship - Advanced Scholars Program alumni. Email: ramadhani.sinde@nm-aist.ac.tz.

Neema Mduma is lecturer the Nelson Mandela African Institution of Science and Technology (NM-AIST) in Tanzania. She has PhD and MSc in Information and Communication Sciences and Engineering from NM-AIST in 2020 and 2016 respectively. Neema is passionate about education particularly girls, and during her PhD, she developed a Machine Learning model called BakiShule which aimed at preventing students from dropping out of school. Neema's efforts towards women in science has been recognized and she was given an award from the L'Oréal UNESCO as 20 young talents in Sub-Saharan Africa for the year 2020. Her research interests are Artificial Intelligence, Machine Learning and Data Science. Email: neema.mduma@nm-aist.ac.tz.

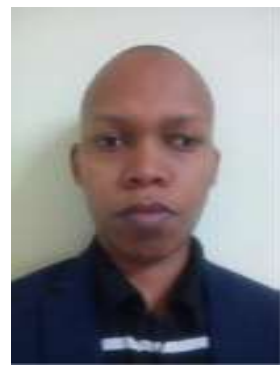

Dr. Mussa Ally Dida is a Senior Lecturer at NM-AIST School of Computational and Communication Sciences and Engineering (CoCSE), Deputy Centre Leader of the Centre of Excellence for ICT in East Africa (CENIT@EA). He has a PhD in Information and Communication Engineering from Beijing Institute of Technology (BIT), China attained in June 2017. He has supervised/ co-supervised 14 Masters and 2 PhD students to graduation and he is currently supervising more than 10 masters and PhD students. He has published more than 40 papers in highly reputable journals. His research interests are in the areas of wireless communication systems, embedded systems, and IT systems development. Email: mussa.ally@nmaist.ac.tz. 